\title{
LIVING CONDITIONS AND HEALTH
}

\begin{abstract}
A
MEDICAL conference on "The Influence of Living and Working Conditions upon Health" was held at Cannes during September 27-29, under the chairmanship of Prof. J. Parisot, former president of the World Health Assembly, and Prof. J. de Castro, formerly president of the United Nations Food and Agriculture Organization. The French Ministry of Health and Atomic Energy Commission were represented.

In the section on nutrition the diverse ways in which food factors operate were discussed on a world level by de Castro, while Cicely Williams laid stress on the social factors that might often exceed the physiological in a given food situation. According to Yang-Fn-Fu, recent examination of the high cereal diet common in China had shown evidence of reasonable adequacy of its vegetable protein with consequently less necessity for substitution by meat; local vegetable foods, fortified by vitamins and minerals, could be expected to correct the main deficiencies of this diet.

D'Arcy Hart considered that the highly efficient chemotherapy now available against tuberculosis imposes some re-thinking on nutritional policy in relation to this disease in under-developed countries. It is imperative to discover whether such chemotherapy is effective in the malnourished, so that mass chemotherapy can be integrated with general social and nutritional improvements; probably host resistance to infection remains important for healing, however potent the drugs may be in the initial stages of treatment. Techniques and factors, particularly
\end{abstract}

psychological, in the study of fatigue in industry were discussed by Desoille and Le Guillant in the section on work factors, while problems of industrial disease in various occupations were presented by other speakers. These include Reysek, who told of some apparently new types of pulmonary exercises being tried in Czechoslovakia for silicotics, which were suggested by observations on glass blowers.

The third main topic on late effects of ionic radiations was introduced by Lacassagne, who concluded that collective moasures, which would restrict the almost inevitable increase in the chance of the total population being exposed to a supplementary dose of such radiations, should not be delayed. The results of a follow-up in 1956 on the changes in blood and
bone marrow in survivors of Hiroshima were given by Kono, who said that, apart from leukæmia, significant abnormalities were found on close examination of some apparently normal persons. Peacock pointed out the possible future carcinogenic dangers from radioactive isotopes. The general view of the speakers seemed to be that practice had outrun experiment and safety tests.

The conference concluded by forming an "International Medical Association for the Study of Health and Living Conditions"*, which, it is assumed, will sponsor the recently published journal Living Conditions and Health, the first two numbers of which have appeared in no less than six languages.

\footnotetext{
- Secretariat: Helferstorferstrasse 4/12/III, Vienna 1.
}

\section{IMMUNITY IN PARASITISM}

“T HE Nature of Immune Responses in Parasitism" was the subject discussed at a meeting of the Parasitology Group, Institute of Biology, on Oetober 18, at 41 Queen's Gate, London, S.W.7. Three speakers were invited to read pepers.

Dr. M. Robertson (Lister Institute) summarized the results of the invostigation into the antibody response of cows and heifers to infection with Trichomonas foetus. This work was carried out in collaboration with Dr. W. R. Kerr, of the Ministry of Agriculture, Northerm Ireland.

The parasite develops in the uterus, and antigen, probably from the breakdown of the trichomonads, passes into the lymph glands and blood stream, resulting in the production of circulating agglutinins. The antibody in the blood stream has no protective value as it does not come into contract with the trichomonads at the site of infection.

The presence of $T$. foetus in the uterus stimulates the local production of antibody, which in acute cases of the disease appears to have a briof protective value in early re-exposure to infection.

Antigen passes out from the uterus, and antibody is produced in the circulating blood; but antibody does not pass back from the blood into the uterus. 'Trichomonads from the uterus appear in the vagina, sometimes in great numbers. Their presence stimulates the appearance of antibody in the vaginal mucin which causes the temporary disappearance of the trichomonads from the vagina, but does not have any value in protecting the animal from re-infection.

The vaginal antibody is probably produced locally. It is of great diagnostic value.

The antibody reactions of the rat to infection with Trypanosoma lewisi were briefly described. The trypanocidal antibody and the growth- and divisioncontrolling antibody, or ablastin, studied by Taliaferro were referred to, and further work on the nature of ablastin was mentioned.

Dr. E. J. L. Soulsby (Cambridge) presented work concerned with immunological responses of the host to helminth infestations.

The way in which immune mechanisms may modify naturally ocurring helminth infestations was briefly indicated, with particular references to gastrointestinal nematodes of sheep. It was shown that the degree of immunity of the host, as messured by antibody-levels, was inversely proportional to the intensity of infestation and to the level of egg production. An almost complete elimination of previously high infestations occurred in early summer, and this was associated with a marked immunological response by the host. Following the elimination of the helminths, a period of protection was estab. lished in the sheep despite persistent reinfestation. 